\title{
Analytical Study on Deformation and Structural Safety of Parafoil
}

\author{
Longfang Wang $\mathbb{D}$ and Weiliang He $\mathbb{B}$ \\ School of Astronautics, Beihang University, Beijing 100191, China \\ Correspondence should be addressed to Weiliang He; heweiliang@buaa.edu.cn
}

Received 29 December 2017; Revised 26 February 2018; Accepted 13 March 2018; Published 1 April 2018

Academic Editor: Filippo Berto

Copyright (c) 2018 Longfang Wang and Weiliang He. This is an open access article distributed under the Creative Commons Attribution License, which permits unrestricted use, distribution, and reproduction in any medium, provided the original work is properly cited.

\begin{abstract}
This study focuses on the cell bump distortion and bearing capacity of parafoil structure. Based on the mechanical properties of the membrane structure, the spanwise model of parafoil inflation was established and verified by comparing with the fluid-structure interaction (FSI) results. Because the internal pressure is very low, the chordwise stiffness is mainly generated by suspending lines. The chordwise model of inflated parafoil was established in consideration of elastic force and aerodynamic force. The results show that the cell is slenderer; the canopy surface is smoother; the aerodynamic load has a light effect on the shrinkage and bump ratios; when the cell width is constant, the critical dynamic pressure reduces $k$ times with the $k$ times increasing in parafoil area; and the design parameters of the first-row line OA have significant effects on the structural stiffness of inflated parafoil. The analytical model is useful for the weakening deformation design and the safety discussion of large parafoil for rocket booster recovery.
\end{abstract}

\section{Introduction}

The parafoil is a flexible wing maintaining the aerodynamic shape with ram air in cells and decelerating the payload drop with aerodynamic lift. The aerodynamic force on canopy can be changed by pulling down the steering ropes to achieve steerable flight. As a kind of steerable aerodynamic decelerator, parafoil gets extensive attention in the rocket booster recovery. The parafoil is made by flexible textile material and presents large deformation during flight. When used in booster recovery, the parafoil has a tremendous area and bears a large wing load. This puts forward higher requirements for the bearing capacity of parafoil structure. Therefore, it is necessary to investigate the deformation and structural stiffness of large parafoils to improve their performance and safety.

The deformed surface geometry of a parafoil was presented by a video-based photogrammetry during tethered testing in a low-speed tunnel $[1,2]$. Due to the fact that this kind of test presents a high cost, numerical simulation has become a popular way to analyze the deformation of parafoils. Kalro et al. set the shape of deformed canopy according to the drop test and analyzed the motion of opening process [3]. Eslambolchi and Johari extracted the inflated canopy geometry from close-up images of the MC-4 canopy during a flight and computed the flow field around the deformed canopy [4]. Ibos et al. simulated the fluid-structure interaction problem of a parafoil using SINPA software [5]. Kalro and Tezduyar calculated the shape of a parafoil in a steady flight using the parallel coupling algorithm for fluid-structure coupling using finite element methods [6]. Fogell et al. analyzed the fluid-structure interaction problem of a single-cell parafoil model [7]. Altmann studied the deformation of canopy by the potential flow theory and the cable finite element $[8,9]$. Peralta and Johari investigated the geometry of a fully inflated canopy in steady flight using a prescribed pressure distribution [10]. Mosseev developed a series of software to simulate the aerodynamic deformation of a canopy [11]. The results indicate that the projected area of an inflated canopy is $18 \%$ smaller than the area of the initial geometry.

The numerical simulation of the fluid-structure interaction in the parafoil is very complicated and timeconsuming. It is difficult to carry out a numerical simulation while designing a parafoil. Besides, the trade studies on design variables cannot be clearly discussed only by the 
analysis of simulation examples. The deformation and safety of the parafoil structure during the flight should be included in the design process in order to improve the flight performance of the parafoil. It is important to find a design theory which is able to guide the manufacture process of large parafoils. The novelty of the current study is to establish the theoretical spanwise and chordwise model for the design of parafoil. Further, the effect of design variables is studied.

\section{Spanwise Structure Model}

As is shown in Figure 1, the inflating deformation of parafoil is mainly embodied as the spanwise bumps. This is determined by the mechanical properties of the membrane structure. The widthwise projection of the ideal cell is flat, but the lengthwise projection is curved. When the cell is ballooning, the widthwise curvature changes more than the lengthwise curvature to bear pressure load. The failure of spanwise structure is the primary failure mode of wingtip collapse. Hence, the chordwise deformation and stress can be neglected in the two-dimensional deformation model of canopy structure.

The stress of membrane structure is expressed below [12]:

$$
\frac{\sigma_{1}}{r_{1}}+\frac{\sigma_{2}}{r_{2}}=\frac{P}{t}
$$

where $\sigma_{1}$ and $\sigma_{2}$ are the radial and latitudinal stresses, respectively; $r_{1}$ and $r_{2}$ are the radial and latitudinal radius of curvature, respectively; $P$ is the differential pressure; and $t$ is the thickness. In the two-dimensional model, (1) is simplified:

$$
\frac{\sigma}{r}=\frac{P}{t}
$$

where $\sigma$ is the canopy stress, and $r$ is the widthwise radius of curvature. The widthwise variation of pressure is neglected, and the canopy stress is constant in each cell, so the cells must be inflated to a circular arc.

Figure 2 presents the 2D geometrical configuration of balloon cells. The ribs are simplified as straight lines and the upper and lower surfaces are simplified as a circular arc with radius $r$. The cell coordinate system is established to analyze the deformation of the cell. The $y$-axis is parallel to the rib and the $x$-axis is perpendicular to the rib. When the parafoil is in steady flight, every cell structure is in equilibrium, and the vector sum of the forces acting upon it is zero. Because the lift of the parafoil is mainly provided by the upper surface, the aerodynamic pressure load is entirely applied on the upper surface. The pressure on the lower surface is equal to the stagnation pressure. By analyzing the forces on the rib, upper and lower surface, the equations are listed as follows:

$$
\begin{aligned}
T_{1} \cos \varphi+T_{2} \cos \varphi & =P_{2} h, \\
2 T_{1} \sin \varphi & =P_{1} w, \\
2 T_{2} \sin \varphi & =P_{2} w,
\end{aligned}
$$

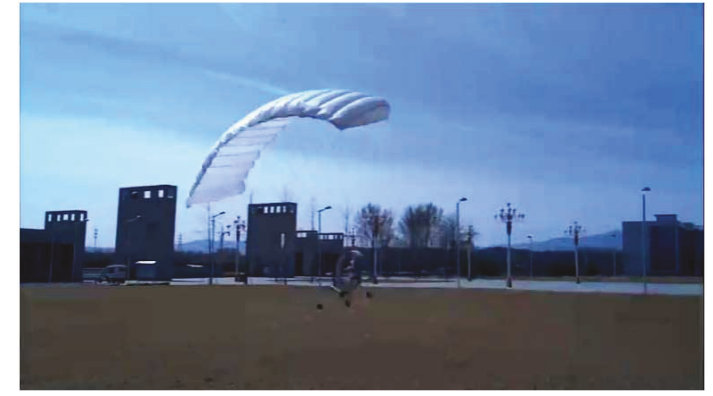

FIGURE 1: Photograph of parafoil in flight.

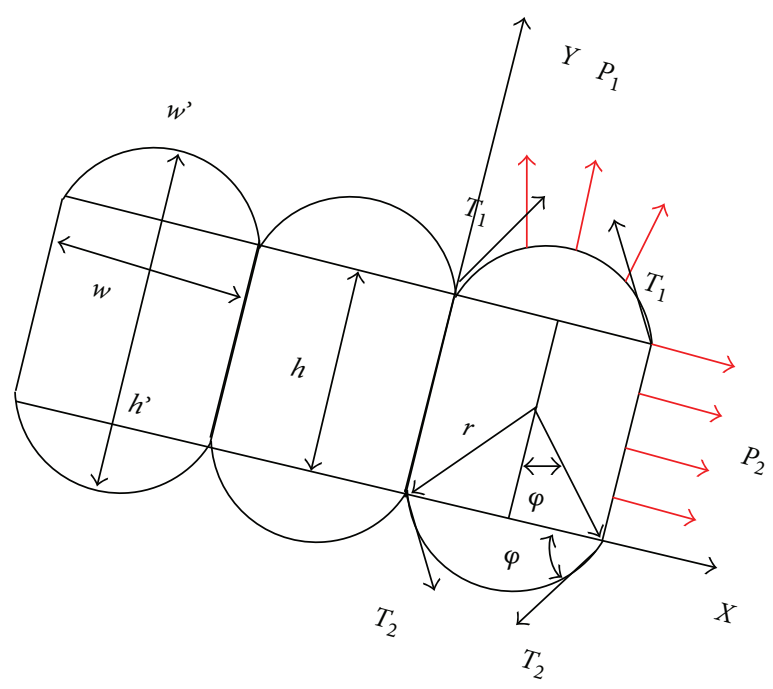

Figure 2: Two-dimensional model of balloon cells.

where $T_{1}$ and $T_{2}$ represent the tensions per unit chord of upper and lower surface, respectively; $P_{1}$ and $P_{2}$ represent the differential pressure on upper surface and the stagnation pressure, respectively; $h$ and $w$ represent the height and width of the cell, respectively; and $\varphi$ represents the half of the central angle.

As is mentioned above, the difference between $P_{1}$ and $P_{2}$ is the aerodynamic pressure load:

$$
P_{1}=P_{2}+\frac{1}{2} \mathrm{CL}^{\prime} \rho V^{2}=\left(1+\mathrm{CL}^{\prime}\right) \frac{1}{2} \rho V^{2}=\left(1+\mathrm{CL}^{\prime}\right) P_{2} .
$$

Here, $\rho$ is the air density; $V$ is the parafoil velocity; and $\mathrm{CL}^{\prime}$ is the lift coefficient defined in the cell coordinate system.

Equation (5) is subtracted from (4) and combined with (6), resulting in (7) below:

$$
T_{1}=T_{2}+\frac{\left(P_{1}-P_{2}\right) w}{2 \sin \varphi}=T_{2}+\mathrm{CL}^{\prime} \frac{P_{2} w}{2 \sin \varphi}=\left(1+\mathrm{CL}^{\prime}\right) T_{2}
$$

Equation (7) is substituted into (3), resulting in (8) below:

$$
\left(2+\mathrm{CL}^{\prime}\right) T_{2} \cos \varphi=P_{2} h
$$


Equation (9) can be derived by the division operation of (8) and (5):

$$
\varphi=\operatorname{atan}\left(\frac{w}{h} \frac{2+\mathrm{CL}^{\prime}}{2}\right)
$$

According to the geometric relationship shown in Figure 2, the ratio between the arc length $w^{\prime}$ and the width $w$ can be indicated as follows:

$$
\begin{aligned}
r & =\frac{w^{\prime}}{2 \varphi}=\frac{w}{2 \sin \varphi}, \\
\eta_{1} & =1-\frac{w}{w^{\prime}}=1-\frac{\sin \varphi}{\varphi}, \\
\eta_{2} & =\frac{h^{\prime}-h}{h}=\frac{2 r(1-\cos \varphi)}{h},
\end{aligned}
$$

where $\eta_{1}$ and $\eta_{2}$ are defined as the shrinkage ratio and the bump ratio of the cell, respectively. Because the cell height is mainly concentrated around the rib peak, the cell height of the parafoil is set as the thickness of the rib. The flexible lines can only restrict the relative position of the intersection point of the lines and the connection point of the ribs; therefore, the ribs can move easily on the arc whose center is the intersection point and radius is the line length. The move is similar to the contraction of the accordion and leads to a large difference between the deformed shape and the design shape of the parafoil.

To validate the spanwise model, the fluid-structure interaction (FSI) simulation using the commercial solver ANSYS has been carried out in our previous work [13]. The grid of the parafoil system is shown in Figure 3. The canopy is divided into triangular membrane elements. The two intersection points of the suspending lines are fixed, and in order to avoid the rigid body motion, the symmetrical boundary condition is applied in the middle of the parafoil. The internal and external pressure distributions on the canopy, which were calculated at the angle of attack of $5^{\circ}$ using CFD method, were transferred to the canopy structure through mapping interpolation. To avoid divergence, the load was applied on the canopy in a way that it increased linearly with the substeps.

The deformed parafoil obtained from the fluid-structure interaction (FSI) simulation is presented in Figure 4. The deformation is not amplified, and its scale is in accordance with the geometric dimensioning of canopy. The bumps of cells are clearly visible. It can be seen from Figure 4(a) that the inflated canopy reduces the span which is equal to the width of two cells. The actual span in the flight reduced by $13 \%$ compared to the designed span. The maximum thickness of the airfoil Clark-Y18 is $18 \%$ c, but it will increase to $26 \%$ c after the bumps appear.

The cell ratio $h / \mathrm{w}$, stagnation pressure $P_{2}$, thickness $t$, and cell lift coefficient $\mathrm{CL}^{\prime}$ in the case shown in Figure 3 are $0.9,61.25 \mathrm{~Pa}, 1 \mathrm{~mm}$, and 0.55 , respectively. These parameters are substituted into (9), (10), and (11), then the shrinkage ratio is $14.6 \%$ and has little

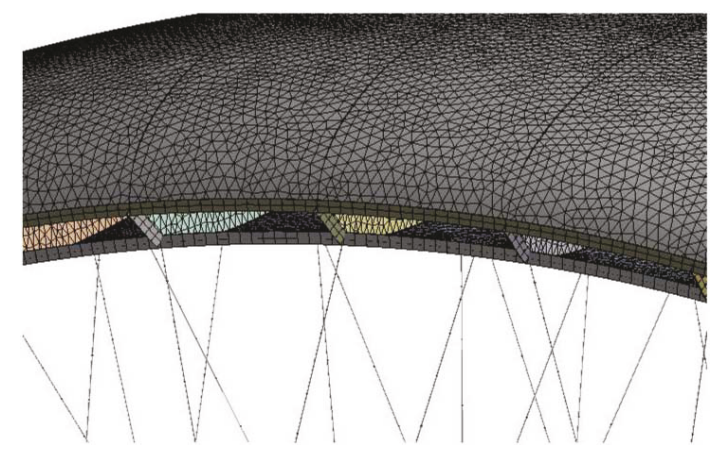

Figure 3: Meshes of the parafoil.

difference with the value of $13 \%$ presented earlier. The radius of curvature $r$ for the cell is $0.1 \mathrm{~m}$. The bump height $h^{\prime}$ is $26 \%$ c and is equal to the previous value of $26 \%$ c. A comparison of the two sets of shrinkage ratio and bump height validates the two-dimensional simplified model. The stress of the lower surface calculated by (2) is $6000 \mathrm{~Pa}$, so the strain of the canopy is very small. The parafoil is a typical large deformation small-strain structure, and the deformation is determined by geometrical configuration rather than material characteristics.

The relationship between the shrinkage/bump ratios and the cell ratio $h / w$ with different $\mathrm{CL}^{\prime}$ values is plotted in Figure 5. When the cell ratio is 1.8 , the bump ratio is very close to the wind tunnel test result $18 \% \mathrm{c}$ to $23 \% \mathrm{c}$ [7]. As can be seen from the curves, the cell is slenderer, the shrinkage ratio and bump ratio are smaller, and the canopy surface is smoother. This is why some high-performance paragliders are composed of numerous cells. When the cell ratio is greater than 2 , the bump ratio changes little, so the design value of 2 is recommended. The cell ratio is decreased, and the shrinkage ratio is increased from the peak to the trailing edge, so the angle of sweepback shows up. The shrinkage and the bump ratios are increased a bit with the increase of $\mathrm{CL}^{\prime}$, and the effect of $\mathrm{CL}^{\prime}$ is great at the medium cell ratio. It means that the aerodynamic shape of the parafoil will change a little with different angles of attack.

The shrinkage and bump ratios are ineradicable. Form rib peak to trailing edge, the cell ratio is monotonously decreasing, consequently, so is the shrinkage ratio. The canopy is made of pieces of cloth. If the pieces of upper and lower surface are designed to be the strips of uniform width, the parafoil is likely to be malformed. The ideal cells of uniform width become wide in the front and narrow in the back after ballooning. This generates the angle of sweepback described previously. In order to guarantee the spanwise appearance, the design of every cell upper and lower surfaces needs to provide margin. A piece of upper or lower surfaces is no longer a rectangular shape. The surcharge is computed by the shrinkage ratio along the chordwise for a CL' value of 0.55. A piece of wider and ideal lower surface for parafoil described previously is shown in Figure 6.

The ribs are made of textile material, so they can only bear tension. The expression for calculating the tension 


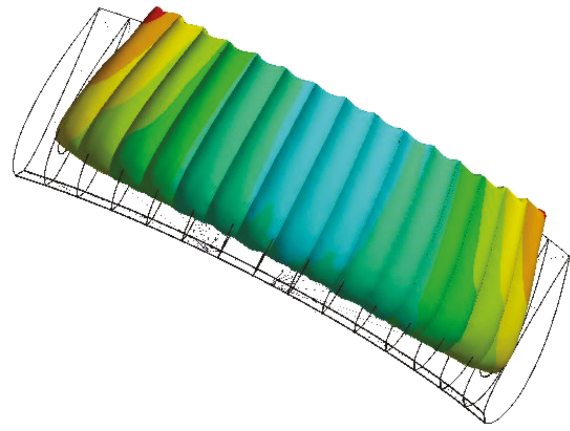

(a) Top view

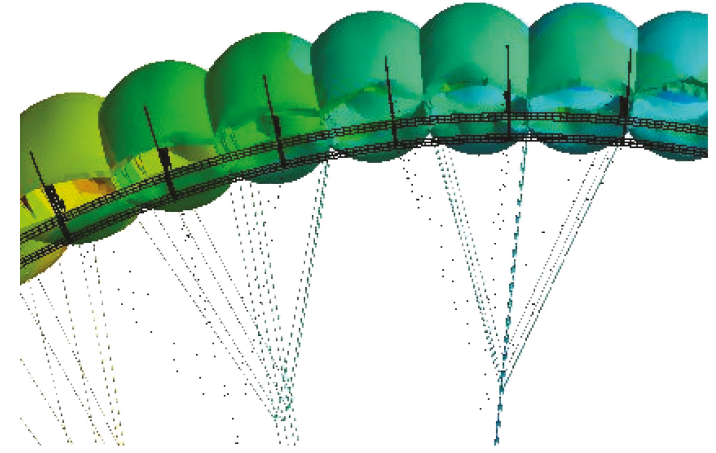

(b) Front view

FIGURE 4: Deformed configuration of a parafoil.

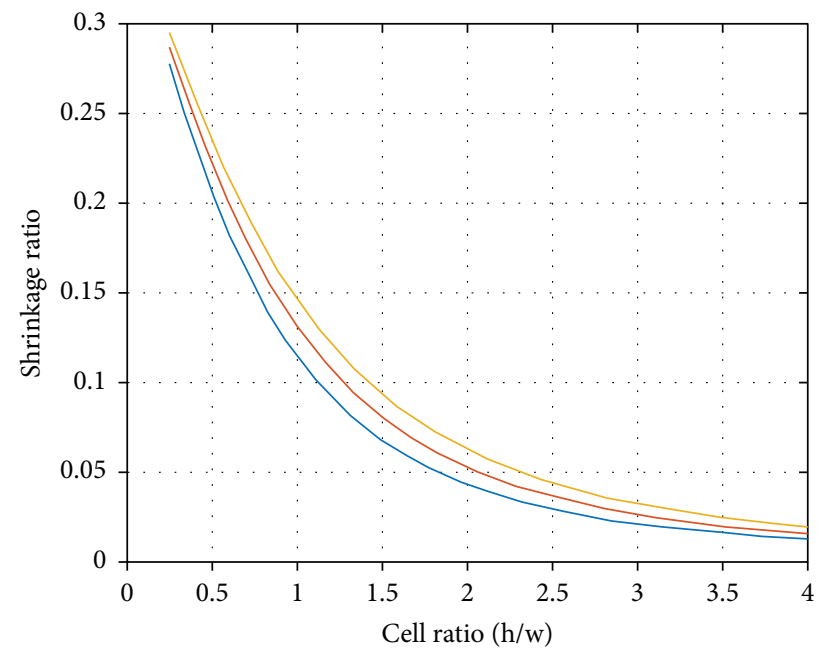

$\mathrm{CL}^{\prime}=0.25$

$\mathrm{CL}^{\prime}=0.55$

$\mathrm{CL}^{\prime}=0.85$

(a) Shrinkage ratio

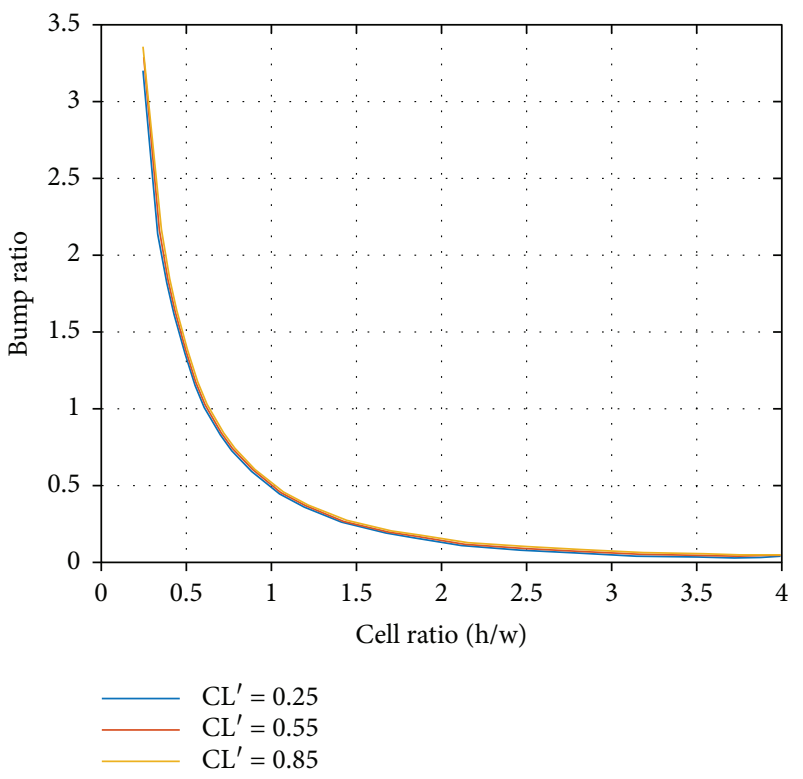

(b) Bump ratio

FIGURE 5: Relationship between shrinkage/bump ratio and cell ratio.

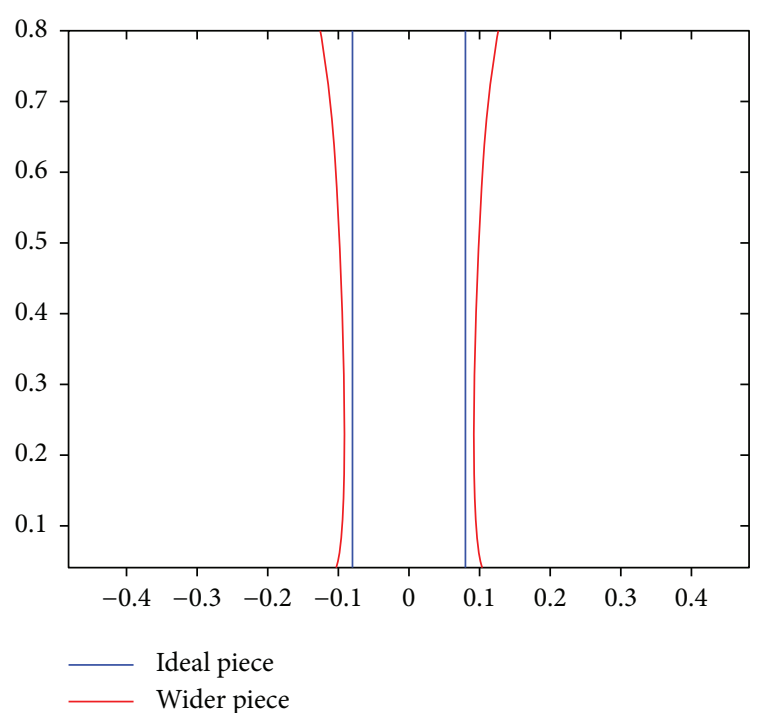

FIGURE 6: Pieces of ideal and wider lower surface. per unit chord of the rib $T_{3}$ can be derived from (4) and (5):

$$
T_{3}=2 T_{1} \sin \varphi-2 T_{2} \sin \varphi=\left(P_{1}-P_{2}\right) w=\mathrm{CL}^{\prime} P_{2} w
$$

Apparently, the tension of the rib is the lift defined in the cell coordinate system. The physical significance is that the ribs and suspending lines are medium for the lift transmission from the upper surface to payload. Compared with the inflated wing [14], the internal pressure of the parafoil is too small, and the bearing capacity of inflated canopy without the tensile suspending line can be neglected. If the tensions of the ribs in some cells become zero, the ribs and suspending lines will be slacked, and the parafoil structure will collapse. According to (15), the critical pressure on the upper surface is $\mathrm{CL}^{\prime} P_{2}$. This critical pressure is not the normal aerodynamic load but the perturbation caused by crosswind. This illustrates that the parafoil with large wing loading has a high ability to resist wingtip collapse. For the flight parameters, the critical pressure is $33.7 \mathrm{~Pa}$ for the 
deformed parafoil shown in Figure 4. This pressure is much lower than the differential pressure of the canopy, which is often considered the critical pressure of wingtip collapse in previous research.

The nonlinear buckling analysis for wingtip collapse of the deformed parafoil shown in Figure 4 was carried out. According to the relationship between the displacement and the load in Figure 7, the critical pressure on the wingtip is $32.9 \mathrm{~Pa}$. The error between this critical pressure and the result above is $2.4 \%$, showing that the two-dimensional model of wingtip collapse can reproduce the phenomena with a low margin of error.

\section{Chordwise Structure Model}

After the inflating deformation of cell, the parafoil can bear aerodynamic load. The inflated canopy should twist under the action of chordwise aerodynamic moment. Compared with the spanwise bumps, the torsion has a completely different mechanism. It is caused by the aerodynamic loading and varied with flow velocity. As is mentioned above, the bearing capacity of inflated canopy without the tensile suspending line can be neglected. The aerodynamic loads of each cell are directly transmitted to payload by the ribs and suspending lines attached on each cell. The force transmission between cells is negligible, so the analysis of the chordwise torsion can focus on a cell and the suspending lines. Hence, the torsion of parafoil can be simplified to two-dimensional chordwise model.

The two-dimensional chordwise sketch of parafoil is shown in Figure 8. Due to the constraint of line OB, the cell in front of line OB can rotate around point $\mathrm{B}$. When the cell presents an upward rotation angle $\theta$ under the aerodynamic moment, the line OA will be stretched and the elongation is $l \theta ; l$ is the distance between points $\mathrm{A}$ and $\mathrm{B}$. Hence, the elastic restoring moment of line $\mathrm{OA}$ is $\left(l^{2} \theta / L_{1}\right) E A$. Here, $L_{1}, E$, and $A$ are the length, elasticity modulus, and sectional area of line OA, respectively. The torsional rigidity of the cell is shown below:

$$
K_{\theta}=\frac{l^{2}}{L_{1}} E A .
$$

The initial angle of attack is $\alpha_{0}$, and the free-stream velocity is $V$. Due to the elasticity of parafoil structure, the new equilibrium at angle of attack $\alpha=\alpha_{0}+\theta$ will be established under aerodynamic load. The additional angle $\theta$ is defined by torsional rigidity and aerodynamic load, but the aerodynamic load is also affected by $\theta$. According to aerodynamics, the aerodynamic load is composed of the lift force $L$ applied on the aerodynamic center and the nearly invariable moment $M_{0}$ about aerodynamic center. The lift $L$ and the aerodynamic moment $M$ about point $\mathrm{B}$ are shown below:

$$
\begin{aligned}
& L=\mathrm{CL}^{\prime} q S=\frac{\partial \mathrm{CL}^{\prime}}{\partial \alpha}\left(\alpha_{0}+\theta-\alpha_{\mathrm{zl}}\right) q S, \\
& M=M_{0}+L f=M_{0}+\frac{\partial \mathrm{CL}^{\prime}}{\partial \alpha}\left(\alpha_{0}+\theta-\alpha_{\mathrm{zl}}\right) q S f .
\end{aligned}
$$

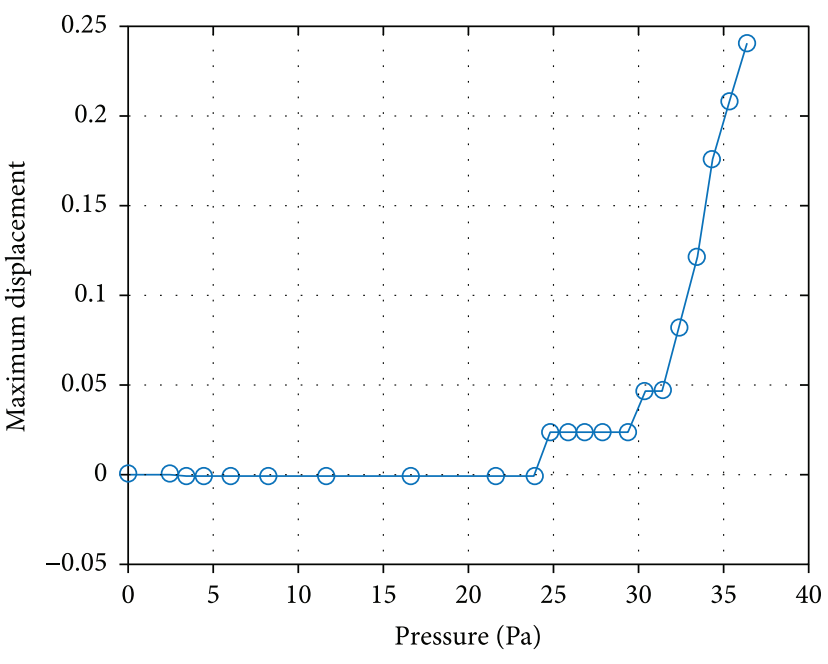

FIGURE 7: Load-displacement curve of deformed canopy.

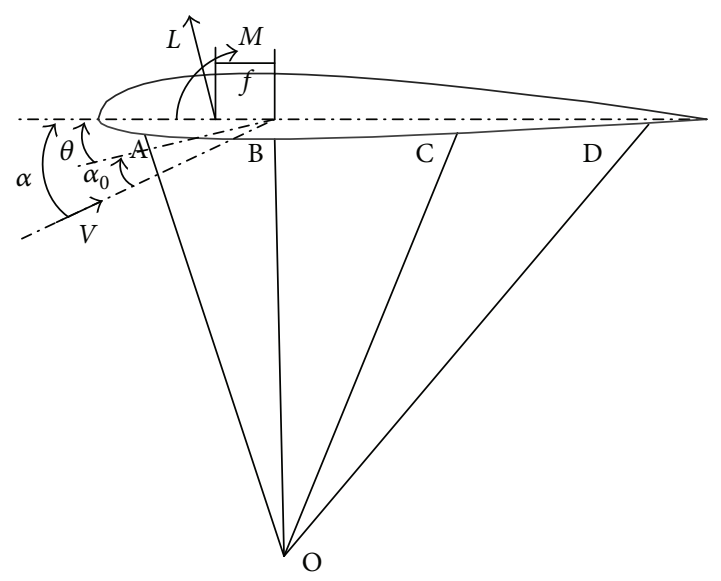

Figure 8: Pieces of ideal and wider lower surface.

Here, $\mathrm{CL}^{\prime}$ is the lift coefficient defined in the cell coordinate system; $q$ is the dynamic pressure; $S$ is the reference area of the cell; $\alpha_{\mathrm{zl}}$ is the zero lift angle of attack; and $f$ is the distance between the aerodynamic center and point $B$.

The aerodynamic moment is equal to the elastic moment, so the equilibrium equation can be written as below:

$$
K_{\theta} \theta=M_{0}+\frac{\partial \mathrm{CL}^{\prime}}{\partial \alpha}\left(\alpha_{0}+\theta-\alpha_{\mathrm{zl}}\right) q S f .
$$

The term $\theta$ is moved to the left:

$$
\left(K_{\theta}-\frac{\partial \mathrm{CL}^{\prime}}{\partial \alpha} q S f\right) \theta=\frac{\partial \mathrm{CL}^{\prime}}{\partial \alpha} q S f\left(\alpha_{0}-\alpha_{\mathrm{zl}}\right)+M_{0} .
$$

Hence, the expression of $\theta$ is shown below:

$$
\theta=\frac{\left(\partial \mathrm{CL}^{\prime} / \partial \alpha\right) q S f\left(\alpha_{0}-\alpha_{\mathrm{zl}}\right)+M_{0}}{K_{\theta}-\left(\partial \mathrm{CL}^{\prime} / \partial \alpha\right) q S f} .
$$


When the dynamic pressure $q$ reaches a particular value, the denominator in the equation becomes zero and $\theta$ is infinity, and the parafoil structure will crash. The critical dynamic pressure $q_{\mathrm{D}}$ can be written as below:

$$
q_{\mathrm{D}}=\frac{K_{\theta}}{\left(\partial \mathrm{CL}^{\prime} / \partial \alpha\right) S f}=\frac{l^{2}}{\left(\partial \mathrm{CL}^{\prime} / \partial \alpha\right) S f L_{1}} E A
$$

This critical dynamic pressure is aerodynamic load of incoming flow, rather than the perturbation load for wingtip collapse discussed in Section 2. According to the equation above, when the cell width is constant, the critical dynamic pressure of the parafoil amplified $k$ times reduces $k$ times. The structure stability of a large parafoil needs special consideration. The similar conclusion can be drawn by the wind tunnel test [2].

The calculating example is a large rectangular parafoil used in rocket booster recovery. Its design parameters are presented as follows: the baseline airfoil is Clark-Y18, the span length is $48 \mathrm{~m}$, and the chord length is $16 \mathrm{~m}$. The front projection of the canopy is a quadrant arc and its radius is $32 \mathrm{~m}$. There are four chordwise join points between the ribs and suspending lines on the lower aerofoil. The diameter of the lines is $3.2 \mathrm{~mm}$ and its material is Kevlar29. The elastic modulus of this material is $97 \mathrm{GPa}$. The lift-curve slope $\partial \mathrm{CL}^{\prime} / \partial \alpha$ defined in the cell coordinate system is $0.044 \mathrm{deg}^{-1}$ and $f$ is $5 \%$ c. According to (14), the torsional rigidity of the calculating example is $25,600 \mathrm{Nm}$. According to (20), the critical dynamic pressure is $5340 \mathrm{~Pa}$. If the maximum dynamic pressure in booster recovery process is larger than $5340 \mathrm{~Pa}$, the recovery mission is likely to fail. Increasing the section area of suspending lines can enlarge the critical dynamic pressure to improve the reliability of recovery.

The large sectional area of suspending lines results in major drag and large weight. The sectional area should be as little as possible under the premise of safety. The relationship between torsion angle $\theta$ and dynamic pressure with different torsional rigidity is plotted in Figure 9. The torsion angle of the calculating example is within the acceptable range. In the case of one-tenth sectional area of suspending lines, the torsion angle is too large. Therefore, the design parameters of line OA have significant effects on the structural stiffness of large parafoil.

\section{Conclusion}

According to the structural characteristic of parafoil, this study has established the spanwise and chordwise structure model of parafoil. The effects of design parameters on deformation and safety of large parafoils are analyzed. This may be useful for the preliminary parafoil design in rocket booster recovery. From the results, the following conclusions are drawn:

(1) Due to the constraint of flexible ropes, after inflation, the parafoil will greatly distort in comparison to its ideal design shape. For the analyzed parafoil with cell

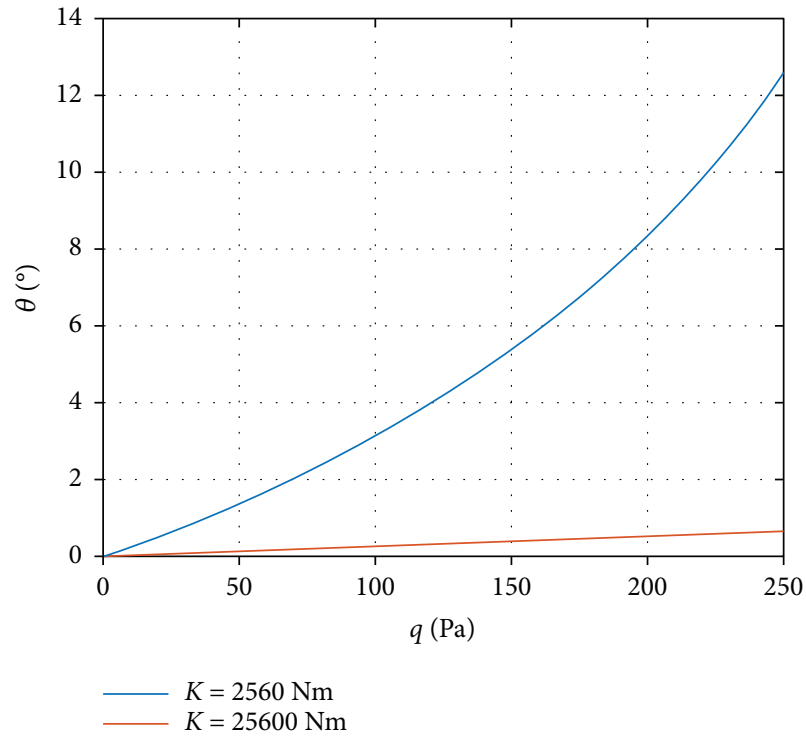

FIgURE 9: Relationship between torsion angle and dynamic pressure.

ratio 0.9 , the actual span of the parafoil reduces by $13 \%$ compared to the designed span; the maximum thickness of the airfoil Clark-Y18 increases to $26 \%$ c after the bumps appear.

(2) The spanwise model is useful for the weakening deformation design and the margin design of the upper and lower piece of the cell. The cell is slenderer and the canopy surface is smoother. The design value of 2 for the cell ratio is recommended. The aerodynamic load has a bit of effect on the shrinkage and bump ratios.

(3) The critical disturbance load of wingtip collapse is much lower than the difference of pressure inside and outside. The parafoil with large wing loading has high ability to resist wingtip collapse.

(4) When the cell width is constant, the critical dynamic pressure reduces $k$ times with the $k$ times increasing in parafoil area. The design parameters of line OA have significant effects on the structural stiffness of large parafoils. Increasing the section area of line OA can enlarge the critical dynamic pressure to improve the reliability of booster recovery.

\section{Nomenclature}

$P: \quad$ Differential pressure

$t$ : Canopy thickness

$\sigma: \quad$ Canopy stress

$r$ : Widthwise radius of curvature

$T_{1}$ : Tension per unit chord of upper surface

$T_{2}$ : Tension per unit chord of lower surface

$T_{3}$ : Tension per unit chord of the rib

$P_{1}$ : Pressure on upper surface

$P_{2}$ : $\quad$ Stagnation pressure 
$h: \quad$ Height of cell

$w$ : Width of cell

$\varphi: \quad$ Half of the central angle

$C^{\prime}$ : Lift coefficient defined in the cell coordinate system

$\eta_{1}$ : Shrinkage ratio of cell

$\eta_{2}$ : Bump ratio of cell

l: $\quad$ Distance between points A and B

$\theta: \quad$ Upward rotation angle

$L_{1}$ : Length of line OA

E: $\quad$ Elasticity modulus line $\mathrm{OA}$

A: $\quad$ Sectional area of line OA

$K_{\theta}$ : Torsional rigidity of cell

$S: \quad$ Reference area of the cell

$f$ : $\quad$ Distance between the aerodynamic center and point $B$.

\section{Conflicts of Interest}

The authors declare that there are no conflicts of interest regarding the publication of this paper.

\section{References}

[1] C. Matos, R. Mahalingam, G. Ottinger, J. Klapper, R. Funk, and N. Komerath, "Wind tunnel measurements of parafoil geometry and aerodynamics," in 36th AIAA Aerospace Sciences Meeting and Exhibit, pp. 1-11, Reno, NV, USA, 1998.

[2] R. H. Geiger and W. K. Wailes, "Advanced recovery systems wind tunnel test report," NASA AD-A238157, Moffett Field, CA, USA, 1990.

[3] V. Kalro, S. Aliabadi, W. Garrard, T. Tezduyar, S. Mittal, and K. Stein, "Parallel finite element simulation of large ram-air parachutes," International Journal for Numerical Methods in Fluids, vol. 24, no. 12, pp. 1353-1369, 1997.

[4] A. Eslambolchi and H. Johari, "Simulation of flowfield around a ram-air personnel parachute canopy," Journal of Aircraft, vol. 50, no. 5, pp. 1628-1636, 2013.

[5] C. Ibos, C. Lacroix, A. Goy, and P. Bordenave, "Fluid-structure simulation of a 3D ram air parachute with SINPA software," in 15th Aerodynamic Decelerator Systems Technology Conference, pp. 1628-1636, Toulouse, France, 1999, , AIAA-99-1713.

[6] V. Kalro and T. Tezduyar, "A parallel 3D computational method for fluid-structure interactions in parachute systems," Computer Methods in Applied Mechanics and Engineering, vol. 190, no. 3-4, pp. 321-332, 2000.

[7] N. A. Fogell, S. Sherwin, C. J. Cotter, L. Iannucci, R. Palacios, and D. J. Pope, "Fluid-structure interaction simulation of the inflated shape of ram-air parachutes," in AIAA Aerodynamic Decelerator Systems (ADS) Conference, pp. 1-15, Daytona Beach, FL, USA, 2013.

[8] H. Altmann, "Numerical simulation of parafoil aerodynamics and dynamic behavior," in 20th AIAA Aerodynamic Decelerator Systems Technology Conference and Seminar, pp. 1-15, Seattle, WA, USA, 2009.

[9] H. Altmann, "Fluid-structure interaction analysis of ram-air parafoil wings," in 23rd AIAA Aerodynamic Decelerator Systems Technology Conference, pp. 1-10, Daytona Beach, FL, USA, 2015.

[10] R. Peralta and H. Johari, "Geometry of a ram-air parachute canopy in steady flight from numerical simulations," in $23 \mathrm{rd}$ AIAA Aerodynamic Decelerator Systems Technology Conference, pp. 1-13, Daytona Beach, FL, USA, 2015.
[11] Mosseev, "Software tools for the paraglider computer-aided design guide," in 16th AIAA Aerodynamic Decelerator Systems Technology Conference and Seminar, pp. 52-61, Boston, MA, USA, 2001.

[12] W. Flügge, Stresses in Shells, Springer, Berlin, Heidelberg, 1973.

[13] L. F. Wang and W. L. He, "Parafoil aerodynamic deformation simulation based on cable-membrane finite element model," Journal of Beijing University of Aeronautics and Astronautics, vol. 43, pp. 47-52, 2017.

[14] Y. C. Gal-Rom and D. E. Raveh, "Simplified aerostructural static model for inflated wings," AIAA Journal, vol. 49, no. 6 , pp. 1180-1190, 2011. 


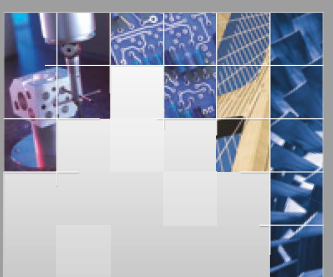

\section{Enfincering}
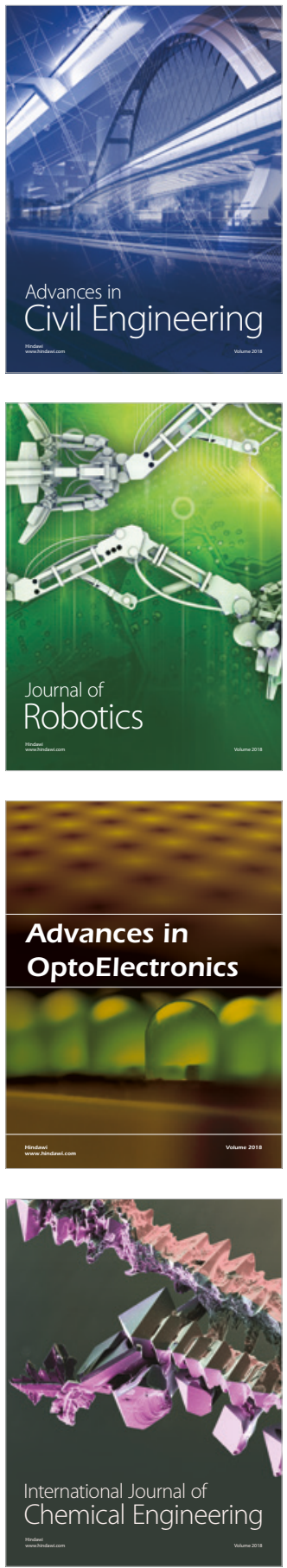

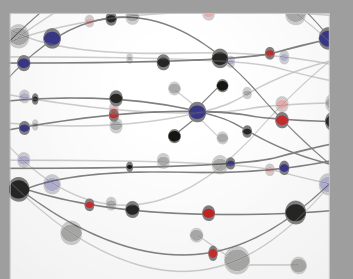

\section{Rotating \\ Machinery}

The Scientific World Journal

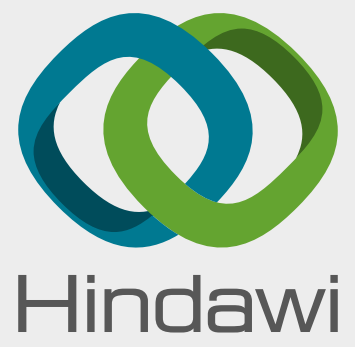

Submit your manuscripts at

www.hindawi.com
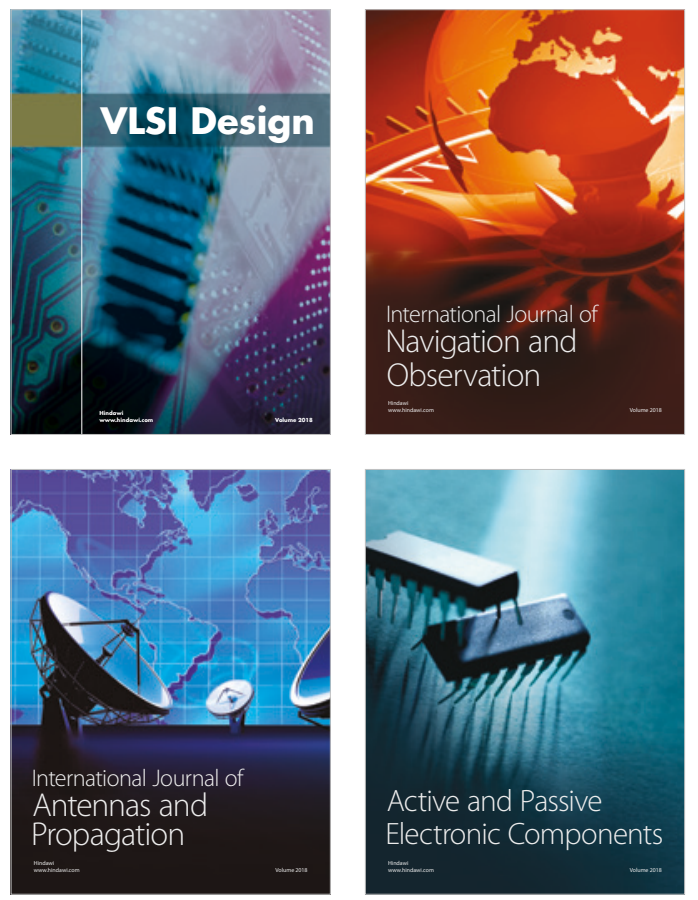
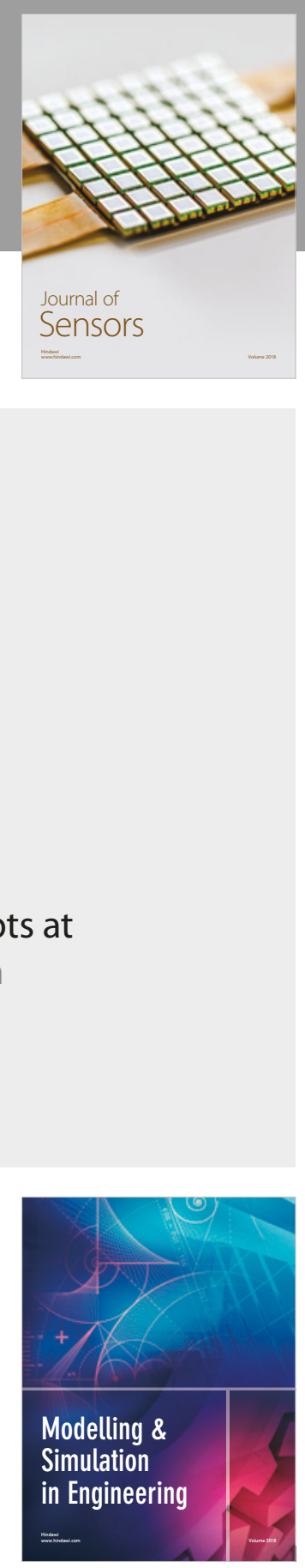

\section{Advances \\ Multimedia}
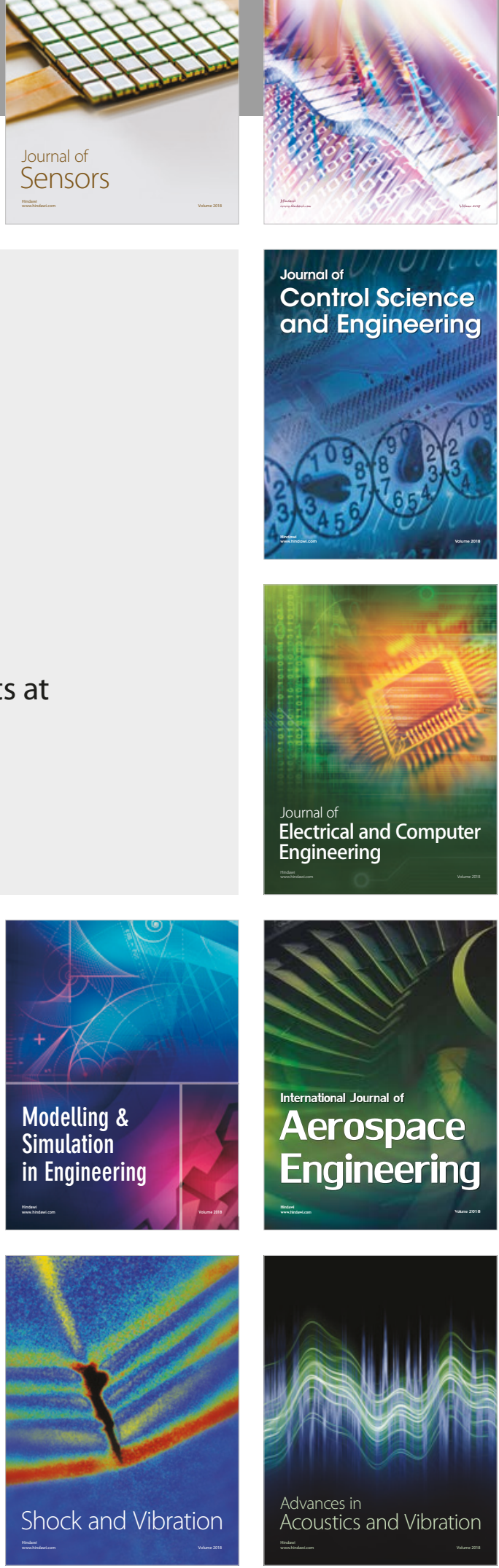